\title{
P211: Organization and scope of infection control in Polish hospitals. First results of the pan-european prohibit survey
}

\author{
A Różańska*, J Wójkowska-Mach, PB Heczko, M Bulanda, the PROHIBIT study group \\ From 2nd International Conference on Prevention and Infection Control (ICPIC 2013) \\ Geneva, Switzerland. 25-28 June 2013
}

\section{Introduction}

The PROHIBIT "Prevention of Hospital Infections by Intervention and Training" survey was initiated to obtain data on practices on HAI prevention and to identify enabling factors or barriers to compliance with evidencebased recommendations.

\section{Objectives}

The paper presents initial descriptive results of a survey on organization of surveillance programs in Polish hospitals, which is a part of PROHIBIT project.

\section{Methods}

Survey was performed by means of the standardized questionnaire in the year 2012. Questions were answered by IC personnel.

Completed questionnaires were obtained from 9 hospitals of different size and type.

\section{Results}

Infection control team (ICT) works in every hospital and the head of the team in 8 hospitals is a physician. In most hospitals number of epidemiological nurses per 100 beds ranges from 0.4 to 0.8 .

In every hospital surveillance comprises all the most important from the epidemiological point of view forms of infections: SSI, BSI, PNEU, UTI, CDI and MDRO - in all wards.

Infection cases in 5 hospitals are documented by epidemiological nurse in collaboration with infection control physician or physician of the ward. In rest - by infection control physician.

Chair of Microbiology, Jagiellonian University Medical College, Kraków, Poland

( ) Biomed Central

(c) 2013 Różańska et al; licensee BioMed Central Ltd. This is an Open Access article distributed under the terms of the Creative Commons Attribution License (http://creativecommons.org/licenses/by/2.0), which permits unrestricted use, distribution, and reproduction in any medium, provided the original work is properly cited.
Most hospitals (7 of 9) also declare running the postdischarge surveillance of SSI.

Feedback on infection rates to HCWs are given twice a year in most hospitals.

In 7 of 9 hospitals consumption of alcohol-based handrub are monitored(average usage is about $101 / 100$ admissions per year). ICTs in all hospitals have access to microbiological data. Average number of blood cultures per 100 admissions/year is 14.8 .

\section{Conclusion}

The results obtained from this small group may suggest that the surveillance programs are complex and well organized.

But, this kind of process measure data are insufficient for assessing the safety of hospitalization which demands the outcomes measure data which are not available in Poland presently. There are just single publications presenting the epidemiological data on infections in Polish hospitals in professional literature what with the low percentage of completed questionnaires suggests the infection control in Poland requires varied educational and practical activities in order to improve safety of hospitalization.

\section{Disclosure of interest}

None declared.

Published: 20 June 2013

doi:10.1186/2047-2994-2-S1-P211

Cite this article as: Różańska et al:: P211: Organization and scope of infection control in Polish hospitals. First results of the pan-european prohibit survey. Antimicrobial Resistance and Infection Control 2013 2(Suppl 1):P211. 